\title{
DRIVING PERFORMANCE THROUGH POSITIVE LEADERSHIP
}

\author{
Sunil Kumar Ramdas ${ }^{\mathrm{a}}$, Harold Andrew Patrick ${ }^{\mathrm{b}}$ \\ a,b Jain University, Bangalore, India \\ ae-mail: rsunilkr@ rediffmail.com \\ be-mail: harold.patrick@ jainuniversity.ac.in
}

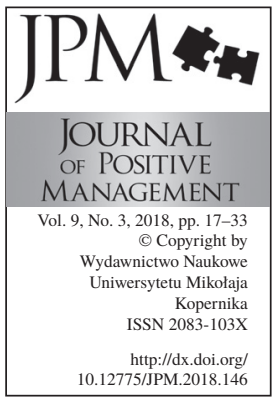

\begin{abstract}
This conceptual paper is an attempt to outline positive leadership and its sub-dimensions. Several progressive theories on positive leadership have observed that, the understanding, developmental process and implementation of positive leadership still remains largely under-researched by scholars from both the fields of leadership and positive psychology. Researchers have identified that good job performance is strongly related to positive style of leadership. The aim of this article is to highlight varied concepts of positive leadership and its meaning. Positive leadership is bascially about respecting people with whom we work, recognising their competencies, contributions, and acknowledging the fact that they are our first customer with whom we do business. It is also about how they shape optimisim as part of the organisational culture over time, formulate positive strategy, introduce positive organisational design and develop available talent using their strengths into potential human capital.

Method: A descriptive methodology was adopted to explore the available literature. The paper presents the concepts of positive leadership, leadership theories that form part of the positive leadership style, approaches and dimensions to positive leadership. They are defined and equated along with similar relationships with other leadership theories or concepts such as transformational, authentic and servant leadership.
\end{abstract}

Findings: The review of literature indicated many similiarities and associations between concepts of positive leadership and leadership behaviour styles. It also found strong relationship between positive leadership behaviour and outcomes such as performace, satisfaction, trust, empowerment, engagement and other critical behaviours that make organisations both effective and efficient.

Keywords: Authentic Leadership; Positive Leadership; Positive Organisational Scholarship; Transformational Leadership; Servant Leadership; Organisational Behaviour

Paper type: Research paper

\section{Introduction}

Individuals who innovate, inspire trust, have long range perspective, focus on developing people strengths and have the ability to translate vision into reality become positive leaders (Bennis, 1989). Research indicates that positive approaches to empower people is a must-have leadership trait and leaders are doing their best to encourage people to grow, contribute, and have meaningful 
DRIVING

PERFORMANCE

THROUGH POSITIVE

Sunil Kumar Ramdas

Harold Andrew Patrick lives (George, 2016). This approach is consistent with the positive psychology, which aims at building, nuturing and developing individual strengths and making peoples lives fulfilling (Seligman, 1986).

Leadership is one of the terms that researchers have attempted to understand or define. Today leadership is the most studied and least understood topic, since we assume that it's a life's phenomenon which is complex and mysterious (Saleh, 2014). From the beginning of the $20^{\text {th }}$ century, leadership has continuously been redefined. Several theories on leadership have been proposed which have redefned leadership on the basis of theoretical perspectives by various researchers. $21^{\text {st }}$ century is marked in the rise of establishing a positive orientation, driven by cultural values, inspiring the workforce to seek a shared vision. Some of the positive leadership theories that are part of the positive leadership style include: Authentic (Avolio and Gardner, 2005; Gardner et al., 2005; George, 2003); Transformational (Bass, 1998; Burns, 1978); Charismatic (Haney, 2012; Glynn and Dowd, 2008; House, 1976; Conger and Kanungo, 1994); Empowering (Nel. et al., 2015; Albrecht and Andreetta, 2011; Hakimi et al., 2010; Arnold et al., 2000; Konczak et al., 2000; Manz, 1990); Servant (Greenleaf, 1970, 1977; Russell and Stone, 2002; Van Dierendonck, 2011), Participative leadership (Yukl, 2011) as well as Ethical and Spiritual leadership (Fry, 2003; Fairholm, 1997) which emphasises on strengths and developments (Youssef et al., 2013). Arakawa and Greenberg (2007) contented that positive leadership has predicted higher employee performance, well-being and is contributing to the effectiveness of organisation and employees.

Leaders who have adopted a positive leadership style are bound to have more engaged employees and deliver better results as leadership behaviour affects trust in workplace, work engagement and psychological empowerment (Patrick and Sunil, 2019; de Klerk and Stander, 2014). The core characteristics that stand out among all the leaders as mentioned above are being authentic, available, transparent, and feel others wholeness (Bennis, 2000). Authentic leaders, try to bring out the best in people by developing others' potential, by empowering people to take responsibility for their actions, and working together to make things better (George, 2016).

Based on the above leadership theories, researchers started looking at positive psychology which has a major influence on leader's behavior. There has been much progress in investigating positive leadership theories in the last fifteen years or so that "the understanding, developmental process, and implementation of positive leadership continous to remain largely under researched by both leadership and recently emerging positive psychology fields (Zbierowski, 2016; Luthans and Avolio, 2003). Positive leadership is distinctive; the leader needs to unleash the strengths and the positive energy for building competencies based on employees' strengths towards good performance, strengthening his team by recognising their 
contribution and having a positive perspective. Two essential qualities that leaders should cultivate are positivity and emotional intelligence (Tombaugh, 2005). This will enable them to bring out the creative power of positivity from the employees and have an impact on the individual and the organisation. Positive leadership has predicted higher employee performance, well-being and is contributing to the effectiveness of organisation and employees. Leaders who engage in positive leadership behaviour style will be able to engage the workforce better leading to higher levels of trust in the workplace, psychological empowerment, more productivity in terms of work engagement, well-being and flourishing.

\section{Why Positive Leadership?}

A positive leader appreciates the positive aspects of challenging times as they are bound to see obstacles as encounters and continue to work persistently to achieve the intended goals. They not only allocate tasks as per the strengths of the employees but also recognises their accomplishment. This creates a feel good factor and awareness about individuals ability to perform the given task by understanding their role and contribution towards the organisation (Quinn and Spreitzer, 1997; Spreitzer, 1995). Positive leaders encourages individuals by providing them a perspective on "what goes right with them, what gives them life, what is experienced as good, what is inspiring and extraordinary" (Cameron, 2008). Seligman (1998) contention was that optimism is as important as competency in achieivng success and can be learned and improvised. As positivity is decisive for leaders in challenging times (Youssef-Morgan and Luthans 2013), as they provide the followers with hope and a "can do" attitude, and lead Seligman (1998), towards positive performance and outcome (Bennis, 1999; Peterson and Barrett, 1987; Nolan-Hoeksema et al., 1986; Peterson and Seligman, 1984). This motivates employees towards their work commitment and ensures their well-being (Furnham et al., 1992). Positive emotions can create a continuous and serious effect on interpersonal relationships across organisation (Fredrickson, 2003) and employees appreciate their leaders ethical behavior by displaying their positive emotions, integrity and fairness (Vianelloa et al., 2010). Positive emotions not only improves employees productivity, quality of work, ability to work in teams and solve problem but also impacts their level of satisfaction at work, creativity, earnings and reduces employee turnover and conflict resolution (Lyubomirsky et al., 2005). Positive behaviors always impacts employees by creating a feel good factor, which raises their performance through trust and engagement.

\section{Evolution of Positive Leadership}

Positive leaders are considered to be influenial on their team members positively and enhance their level of engagement and well-being. It is an optimistic descriptive style that focuses on employees' strengths with a positive approach 
DRIVING

PERFORMANCE

THROUGH POSITIVE

Sunil Kumar Ramdas

Harold Andrew Patrick to situations and recognises their accomplishments (Arakawa and Greenberg, 2007; Krueger and Killham, 2005). Cameron (2010) refers "Positive leadership to the implementation of the multiple positive practices that help individuals and organisations achieve their highest potential, flourish at work, experience elevating energy and achieve levels of effectiveness difficult to attain otherwise". Similiarly Youssef et al. (2013) "looks at the systematic and integrated manifestation of leadership traits, processes, intentional behaviours and performance outcomes that are elevating, exceptional and affirmative of the strengths, capabilities and developmental potential of leaders, their followers and their organisations over time and across contexts". Positive leadership is part of positive orientation and a key variable at the organisational level, The characteristics that build these are embedded in individual behaviour (Zbierowski and Góra, 2014). "Positive leadership tries to stretch what seems possible and raises the bar by lifting teams to greater performance and pleasure" Bremer (2015). Positive leadership is all about how we treat our employees at workplace, as they are the internal customers with whom we interact on an everyday basis. They have a positive explanatory style, which acts as a catalyst to several variables towards organisational performance (Nel et al., 2015). "Positive leadership is a way to lead, inspire and build a great culture by bringing employees together in the face of adversity, develop a connected and committed team and achieve excellence and superior results" (Gordon, 2017).

Positive leadership aims for positive deviance and perform beyond expectations to their best potential.They align closely with business strategy to drive higher levels of performance and brings people together around a shared purpose by empowering them to create value for all stakeholders. By using principles propounded from behavioural and positive theories to promote efforts such as thriving at work, interpersonal flourishing, high moral standards, positive emotions, and energising networks through a) positively deviant performance i.e., focus is on results that drastically exceed common or expected performance, b) affirmative bias i.e, focusing to enable, thrive and flourish least as much as addressing hurdles and impediments and c) facilitating employee friendly environment in an organisation. This creates an atmosphere where there is better co-ordination and involvement among employees in terms of engagement and development, motivation towards commitment and flourishing (Furnham et al., 1994; Furnham et al., 1992).

Positive leaders look at problems as challenges and reach out to situations with a positive aspect and peruse in a planned manner to reach their objectives by adapting, showing control, positive perspective by regularly encouraging, appreciating, recognising and stimulating employees with compliments to produce better results through positive engagements. Positive emotions can be found between interpersonal relationships such as leader-follower interactions 
and then extend to organisation (Fredrickson, 2003). Today, more attention is paid to leaders who respond with positiveness along with ethical behavior of being fair and having moral values such as being authentic, caring, having transparent communication, trustworthiness and recognising employee efforts (Bremer, 2015).

\section{Approaches to Positive Leadership}

One of the pillars of positive organisational scholarship (POS) is authenticity and various aspects with reference to POS are meainingless if they are not factual and accurate. Positive psychologists look at authenticity as one's own experiences (thoughts, emotions, beliefs) and acting in accordence with the true self (i.e., behaviour and expression, what an individual contemplate and consider). As a result, authentic leadership is based on genuineness and values, beliefs, and behaviours that influence his/her followers development. Such leaders never indulge in intimidiation or even persuasion. Researchers have studied frameworks and approaches such as authentic leadership, fundamental state of leadership, positive deviance, strength-based leadership, leader's perspective and recognition $\&$ encouragement that has an influence and impact on the followers. The various approaches are explained in brief for better understanding.

Zbierowski (2016); Hao Meng et al. (2016); George (2006) authentic leadership is accepted as a positive leadership behaviour due to its transparency, ethical/moral and positive/ style of functioning. Which is effectively used to endorse positive attitude (e.g., job satisfaction) and behaviors (e.g., creativity) among followers (George, 2003; Luthans and Avolio, 2003). It is the leader ability to bring people together to achieve sustainable results over time (George, 2006). This contributes towards building trust in workplace and psychological safety (Luthans and Avolio, 2003). This approach to leadership lay emphasis on developing leader's acceptability by way of transparent association with his supporters for considering their views /ideas and developing them on ethical principles. This enables to improve individual and team performance .Walumbwa., Avolio., Gardner.,Wernsing., and Peterson (2008) introduced four principles of authentic leadership - (1) Self-awareness (2) Relational transparency (3) Balanced processing and (4) Internalized moral perspective.

Another concept of positive leadership i.e., fundamental state of leadership was developed by Quinn (2005). The spirit is to answer these four questionion put forth by Quinn (2005) "Am I results centered? (Am I willing to leave my comfort zone to make things happen?). Am I internally directed? (Am I behaving according to my values rather than bending to social or political pressures?). Am I other focused? (Am I putting the collective good above my own needs?). Am I externally open? (Am I receptive to outside stimuli that may signal the need for change?)". Quinn claims that the state of mind changes, by asking and answering these questions, fresh thoughts, feelings, behaviour and technique emerge, and 
DRIVING

PERFORMANCE

THROUGH POSITIVE

Sunil Kumar Ramdas

Harold Andrew Patrick the individual exhibits an array of influence due to change. Yet, the important question in reaching the fundamental state of leadership is who am I ? (What are my values?; What would I never compromise?) Anding and Qiunn (2005). Here the fundamental state of leadership seeks from emotional intelligence as well as self-awareness. Quinn (2005) contends that Individuals who view distintion or eminence look at what their "conceptual tools permit them to see". Fundamental state of leadership has to be treated as a state of awareness, which can be achieved by bringing together elements such as (1) results orientation, (2) internal direction, (3) other focus, and (4) external openness. Two more attributes of fundamental state of leadership can be noticed. Firstly, it might not be fully conscious as people could arrive at fundamental state of leadership without even knowing it. Secondly, it is a temporary state where people enter and exit it as victims of entropy.

Positive deviance succeeds as the final concept of positive leadership theory (Cameron, 2008) stated in his book titled "Positive Leadership". It is a behavioural and social change approach on the basis of observation. Where individual's successful behaviour or approaches enable them to find better solution at workplace in similaiar situations than their co-workers. Positive deviance could emerge as a base for innovation that is indiginous to regular practices or habits, rather than deviance from regular practices or habits. Researchers put forward that few leadership styles and behaviours may stimulate positive deviant behaviour, for example, transformational leadership (Recker and Mertens, 2017: Spreitzer and Sonenshein, 2004). The difference between individual and organisational level of positive deviance is that organisational deviance consists of intended, exit from referent group norms. It is either a harmful or an honorable nature. These are measurable components and positive deviant behaviour, "voluntary, purposeful, and discretionary, rather than forced or coerced" (Spreitzer and Sonnenshein, 2004). Later Cameron (2008) states that positive leadership referes to (1) facilitation of positively deviant performance, (2) affirmative bias and (3) focuses on accomodating the finest of human condition, or bring about virtuousness enabling positive performance by emphasing on what elevates individuals and systems towards predictable performace, fostering high aspiration and being inspirational or charismatic (Cameron, 2010). Positive leaders focus on elements that are positive in nature like climate, relation, communication and meaning would result in positve deviant performance. There is enough indication to put forward that positive leadership develops strength-based positive organisational culture and suitable change management practices to meet the orgnanisational goals.

Zbierowski (2016), analyses the three positive leadership approaches and discloses that they are possibly not placed on the same platform in leadership process. Positive deviance is well-defined in categories of results, as the final state of organisation that should be achieved by positive leadership. Therefore, 
suggest that both authentic leadership and fundamental state of leadership might lead to fulfilling positive deviance and by focusing on honesty and realationship with followers, the kind of climate, meaning, relationships and communication is attainable by supervising the power that is highlighted in positive deviance concept. Self-awareness is the fundamental issue in both authentic leadership and fundamental state of leadership, and is very closely connected to transformational leadership and servant leadership. Servant leadership is based on optimisim. Liden et al. (2014) state that "servant leadership signifies a positive approach to organisational behaviour and the application of positively oriented human resource strengths and psychological capacities that can be measured, developed and effectively managed for performance improvement in today's workplace".

\section{Dimensions of Positive Leadership}

Positive leadership is inspiring, unique and favourable towards one's strengths, and capabilities towards developing their competencies. Arakawa and Greenberg (2007) stresses that positive leadership concept is about (a) strengths-based approach, (b) perspective approach and (c) Recognition and encouragement.

Positive leader needs to foster on strengths focus -building people strengths (Cameron, 2010) to effectively use their own strengths and capabilities by providing employees an opportunity to build their skills which can be utilised for better performance. Hartog and Belschak (2012) say that 'leadership behaviour strengthens individuals self-efficacy'. Positive organisational behaviour focuses on individual strengths that are gauageable and their utility in the workplace, Andony et al. (2016). Self-sacrificing leaders positive influence strengthens followers self-esteem and their relationship with the organisation to have a positive affect. By strengthening positive attitudes, and enhancing high standards of ethical organisational behavior (Vianello et al., 2010) to engage in positive deviance (Recker and Mertens, 2017). Clifton and Harter (2003) say that 'strength-based organisations do not neglect weaknesses, but rather develop their competencies to overcome short commings'. So employees who perform based on their strengths excel and enjoy their tasks assigned. Linley and Harrington (2006) strength as a base creates a natural phenomena of function towards performance in the pursuit of valued outcomes. Research indicates that strengths used by leaders influence followers towards well-being (Nel et al., 2015; Zbierowski and Gorab, 2014; Proctor et al., 2011; Wood et al., 2011; Diener, 2000). Positive leadership is unique as it focuses on employees strengths to develop their competencies (Schon and Beechler, 2014) towards good performance and strengthens the team. Strengthsbased approach is an important component of positive leadership approach.

The leaders positive perspective approach is a key component of positive leadership behaviour and it plays a significant role in managing the uncertainity of change (Arakawa and Greenberg, 2007; Henry, 2005) due to individual's display 
DRIVING

PERFORMANCE

THROUGH POSITIVE

Sunil Kumar Ramdas

Harold Andrew Patrick of control perceptions and to implement strategies that reduces the stumbling blocks and looks at the pitfalls as opportunity for growth and development. Positive perspective includes de-catastrophizing setbacks, where one needs to cope up emotionally by dis- engaging as per circumstance, having accurate control over perception and being able to interpret problems by providing solutions which supports finding on resiliency (Reivich and Shatte, 2002; Arakawa and Greenberg, 2007). It is important to understand the limitation of ones own perspective and being rational about others view point, which increase leaders ability to lead employees across cultures (Zbierowski et al., 2014; Youssef et al., 2013; Helland and Winston, 2005). Which contributes towards meeting the organisation expectation and flourshing of employees. Spreitzer and Cameron (2012) by adopting alternative perspective and (Clifton, 2000) addressing positive psychology from a leadership perspective will enhance positive occurance and by focusing on it, (Maidique, 2013) and providing a solution-oriented perspective.

Recognition and Encouragement is an important aspect, where an individual is recognised or appreciated or acknowledged for some thing they have contributed towards a certain task. Recognition and encouragement forms a positive perspective, which influences trust in workplace and empowerment (Patrick and Sunil, 2019). These factors develop a work environment of dedication, meaningful engagement and satisfaction (Kelloway et al., 2013; Youssef et al., 2013; Brun and Dugas, 2008; Arakawa and Greenberg, 2007; Meyer and Allen, 1991). These enhance better performance, productivity and well-being (Henryhand, 2009: Linley et al., 2007; Grawitch et al., 2006; Luthans, 2000). When employees are recognised and appreciated, it strengthens the emotional value to leverage higher productivity and longevity in the organisation.

"Positive feedback or appreciation enhances intrinsic motivation, whereas negative performance feedback diminished it " (Ryan and Deci, 2000). When immediate supervisors who offer regular recognition and encouragement saw an increase in productivity of $31 \%$ (Arakawa and Greenberg, 2007). Fredrickson and Losada (2005) whenever there is encouragement, the performance of the team performing positively goes up, than negative interactions. Kouzes and Posner (1999) observed that $98 \%$ of respondents responded "yes" to the question, when you get encouragement, does it help you perform at a higher level"? Immediate supervisors who provided frequent recognition and encouragement FRE(E) had significantly higher project performance. Just like goals, frequent recognition and encouragement needs to be specific. In addition, $\operatorname{FRE}(\mathrm{E})$ needs to be genuine. Acknowledging "nice job" is not sufficient and can sometimes be considered as dishonest.

"Positive image leads to positive action, creating a sense of belonging, hope, and optimism about change by sharing that there is going to be a tomorrow, and by reminding people that they can do things beyond themselves" (Bennis, 2000). 
Positive leaders emphasise on individual and organisation development through optimisim. Research indicates that good job performance significantly correlates with positive style of leadership (Arakawa and Greenberg, 2007; Seligman and Schulman, 1986). If organisations need to flourish they need to have leaders with positive behaviour and attitude towards organisation and employees. Take advantage of the heliotropic effect, managing economic downturns virtuously, focusing on abundance gaps, creating positive energy in the face of decline, and implementing positive practices even in industries that don't seem to value them are all keys to flourishing in challenging times (Cameron, 2010).

\section{Why is positivity so critical for leaders?}

The positive behaviour and attitude of a leader not only energises the leader, but it also inspires the team to strive towards their objectives. Alan Mulally, Ford's CEO, during their positive transformation period in 2006, describes his leadership style as "positive leadership-conveying the idea that there is always a way forward". He says a critical part of positive leadership is "reinforcing the idea that everyone is included. When people feel accountable and included, it is more fun. It is just more rewarding to do things in a supportive environment (George, 2016).

The leaders behaviour has an effect on his followers, whether they like it or not. A leaders personality affects an organisation. Therefore it is important to have a positive approach . Which will influence the followers. Since positivity does create positive outcomes. Leaders are transparent about their vision and expectations. Which engenders trust and confidence among followers to look beyond call of duty. Positive leaders set the mood of the workplace and create a long-term culture over time. Due to positive perspective, obstacles and challenges are not looked as road blocks but opportunities. They take on challenges and move forward towards their objectives. However, if there is appreciation and positive feedback, they tend to be more engaged leading to better productivity. Positive behaviour inspires and motives, and there is no looking back. Gordon (2017) indicates that " great leaders understand that people drive the numbers, not the other way around. To win, you must win with people. And it all begins with your decision to become a positive leader, and the understanding that leadership is not just about what you can do, but what you can inspire, encourage, and empower others to do".

Great leaders are always optimistic since they know it supports their personality, and their followers, be more productive and reach their goals. They build relationships with followers, which is crucial by being authentic, caring and giving them the required attention. The research evidence is compelling: applying positive leadership makes a difference in trust in workplace, empowerment, engagement, productivity, satisfaction, and happiness at work (Patrick and Sunil, 2019; Bremer, 2016). Working with positive leaders, makes team members 
DRIVING

PERFORMANCE THROUGH POSITIVE

Sunil Kumar Ramdas Harold Andrew Patrick positive, confident and develop their competence (Bremer, 2018; Goleman et al., 2002). Some theorists even say that we affect people at least three levels out beyond ourselves. Imagine a "contagion" of positivity, spreading because you decided to make a difference! "Positive leadership looks simple but to practice it consistently requires (inner) work. Like anything, it's easier said than done. It requires managing your self-talk, embracing positive possibilities and dealing with your inner critic (and those outside)" (Bremer, 2015).

\section{Conclusion}

"Leaders positivity brings out the best among their followers individually and collectively such as to know and understand each other by true obligation, being transparent and inspiring trust, sharing a task that engages followers to be positive at the workplace" (Bennis, 2000). Positive leaders need to cultivate wellbeing among employees, such as cultivating positive relationship, developing their strengths, inspire to find purpose, being resilient and mindful which will have an impact on performance.

Positive leadership concept have put forth several approaches ancillary to affirmative biases, behaviours and performances resultsing in meaningful engagement and flourishing. Among the various leadership models, fundemental state of leadership, authentic leadership are overlapping. In both, fundamental issue is human emotions and self-awareness. Which covers value systems, strengths and weakness. At the same time, stressing on building meaningful relationship between leader and followers. Authentic leadership stress on transparent relationship and fundamental state of acceptence of views and ideas of followers, whereas positive deviance looks at positive behaviour.

A reliable measuring vaild tool Positive Leadership Measure (PLM), was developed by Arakawa and Greenberg (2007) to measure positive leadership with three subscales - (i) Strengths-based approach, (ii) Positive Perspective and (iii) Recognition. Strengths based leadership is matching abilities to perform one's duties by appreciating and directing on individuals strengths. Positive perspective is about emotional coping, solution orientation and positive interpretation of the problem. while recognition emphasis on acknowledging employee's efforts and accomplishment.

Authentic leadership and fundamental state of leadership might lead to fulfilling positive deviance by focusing on honesty and developing realationship with followers by appreciating their strengths, perspectives and acknowledging their efforts. Its about managing relationships and level of motivation as emphasised in positive deviance concept. Analysis of these positive leadership approaches divulges that they are perhaps not positioned at equivalence in leadership process. As authentic leadership and fundamental state of leadership may lead to attaining positive deviance.This is managed through relationships 
with followers, as emphasised in positive deviance concept. Through the leadership literature it is always observed that there is similiarities between positive leadership and leadership concepts such as servant and transformational leadership. The key to both these is the effect of relationship between the leader and followers, as both authentic leadership and fundamental state of leadership is interrelated to transformational leadership and servant leadership.

Among transformational leadership dimensions, followers influences' are linked to positive approaches to leadership. Servant leadership is associated with positive way of organising. It focuses on "the application of positively oriented human resource strengths and psychological capacities that can be measured, developed, and effectively managed for performance improvement in today's workplace" (Liden et al., 2014). The leadership models have always looked towards positivity, they move the balance from developing performance of supporters (transformational leadership) by assisting in their growth and wellbeing (servant leadership) and building relationships based on transparency (authentic leadership). By understanding oneself and one's relationship with followers (fundamental state of leadership) and by empowering to achieve confidence, but also positive deviance. The three dimensions of positive leadership will guide in mapping the pattern of leadership behaviour among their followers and how to develop these based on the organisation needs. Effective leaders apply the principles of positive psychology, ensuring their interactions with employees contain a healthy balance of positive and constructive feedback. However, they maintain an optimistic outlook despite the setbacks, reinforcing that there is a hopeful way forward (George, 2016). Applying positive leadership makes a difference in trust in the workplace, empowerment, productivity, satisfaction, and well-being.

The future of positive leadership model on research will be reliant on explanation of those concepts especially fundamental state of leadership and positive leadership dimensions such as strengths, perspective and recognition. As researchers need to look at the big picture of the influence of positive leadership and its relationship with other leadership models including their dimensions, which will bring in more clarity towards the behaviour of positive leadership. At the same time look at the possible antecedents and consequences of positive leadership. These will bring new dimensions and perspectives towards organisation building through positive leadership.

\section{References}

Albrecht, L.S., Andreetta, M. (2011), “The influence of empowering leadership, empowerment and engagement on affective commitment and turnover intentions in community health service workers: Test of a model", Leadership in Health Services, Vol. 24 No. 3, pp. 228-237. DOI: 10.1108/17511871111151126 
DRIVING

PERFORMANCE THROUGH POSITIVE

Sunil Kumar Ramdas Harold Andrew Patrick
Anding, M., Quinn, E.J.R. (2005), “An Interview with Robert E. Quinn Entering the Fundamental State of Leadership: Reflections on the Path to Transformational Teaching", Academy of Management Learning and Education, Vol. 4 No. 4, pp. 487-495. DOI: 10.5465/AMLE.2005.19086790

Andony, T., Gorjian, N., Finkelman, J. (2016), "Effects of positive leadership and flow on employee well-beingthrough the PERMA Lens", Austin Journal Psychiatry Behavior Sciences, Vol. 3 No. 1, pp. 1-11.

Arakawa, D., Greenberg, M. (2007), "Optimistic managers and their influence on productivity and employee engagement in a technology organisation: Implications for coaching psychologists", International Coaching Psychology Review, Vol. 2 No. 1, pp. 78-89.

Arnold, J.A., Arad, S., Rhoades, J.A., Drasgow, F. (2000), “The empowering leadership questionnaire: The construction and validation of a new scale for measuring leader behaviors", Journal of Organizational Behavior, Vol. 21 No. 3, pp. 249-269. DOI: 10.1002/(SICI)1099-1379(200005)21:3<249::AID-JOB10>3.0.CO;2-\#

Avolio, B.J., Gardner, W.L. (2005), "Authentic leadership development: Getting to the root of positive forms of leadership", The Leadership Quarterly, Vol. 16 No. 3, pp. 315-338. DOI: 10.1016/j.leaqua.2005.03.001

Bass, B.M. (1999), "Two decades of research and development in transformational leadership", European Journal of Work and Organizational Psychology, Vol. 8 No. 1, pp. 9-32. DOI: 10.1080/135943299398410

Beechler, S. (2014), "Positive leadership: success without collateral damage", available at: https://knowledge.insead.edu/blog/insead-blog/positive-leadership-success-withoutcollateral-damage-3123

Bennis, G.W. (1989), "Managing the Dream: Leadership in the $21^{\text {st }}$ Century", Journal of Organizational Change Management, Vol. 2 No. 1, pp. 6-10. DOI: $10.1108 / 09534818910134040$

Bennis, G.W. (1999), “The leadership advantage”, Leader to Leader, Vol. 1999 No. 12, pp. 18-23.

Bennis, G.W. (2000), Managing the Dream: Reflections on Leadership and Change, Perseus Publishing. Cambridge.

Berscheid, E., Walster, E.H. (1978), Interpersonal Attraction, Addison-Wesley, Reading.

Bremer, M. (2015), "Positive leadership starts with one uplifting person. Will that be you?", available at: https://www.leadershipandchangemagazine.com/positiveleadership-will-that-be-you/

Bremer, M. (2016), "Positive Leadership: Why it's crucial for Organizational Change", available at: https://www.ocai-online.com/blog/2016/10/Positive-Leadership-Whycrucial-for-Organizational-Change

Bremer, M. (2018), "How could I develop a positive culture?", available at: https://www. leadershipandchangemagazine.com/how-could-i-develop-a-positive-culture/

Brun, J., Dugas, N. (2008), "An analysis of employee recognition: Perspectives on human resources practices", The International Journal of Human Resources Management, Vol. 19 No. 4, pp. 716-730.

Burns, J.M. (1978), Leadership, Harper and Row, New York. 
Cameron, K.S. (2008), Positive leadership: Strategies for extraordinary performance, Berrett-Koehler, San Francisco.

Cameron, K.S. (2010), "Five keys to flourishing in trying times", Leader to Leader, Vol. 2010 No. 55, pp. 45-51.

Clifton, D.O. (2000), "Positive management: New perspectives on leadership and employee well-being”, The Psychologist-Manager Journal, Vol. 4 No. 2, pp. 125-127. DOI: $10.1037 / \mathrm{h} 0095886$

Clifton, D.O., Harter, J.K. (2003), "Investing in Strengths", in: Cameron, K.S., Dutton, J.E., Quinn, R.E. (Eds.), Positive Organizational Scholarship: Foundations of a New Discipline, Berrett-Koehler Publishers, pp. 111-121.

Conger, J.A., Kanungo, R.N. (1994), “Charismatic leadership in organizations: Perceived behavioral attributes and their measurement", Journal of Organizational Behavior, Vol. 15 No. 5, pp. 439-452. DOI: 10.1002/job.4030150508

de Klerk, S., Stander, M.W. (2014), "Leadership empowerment behaviour, work engagement and turnover intention: the role of psychological empowerment", Journal of Positive Management, Vol. 5 No. 3, pp. 28-45. DOI: 10.12775/JPM.2014.018

den Hartog, D.N., Belschak., F.D. (2012), "When does transformational leadership enhance employee proactive behavior? The role of autonomy and role breadth self-efficacy", Journal of Applied Psychology, Vol. 97 No. 1, pp. 194-202.

Diener, E. (2000), "Subjective well-being: The science of happiness and a proposal for a natural index", American Psychology, Vol. 55 No. 1, pp. 34-43. DOI: 10.1037/0003066X.55.1.34

Fairholm, G.W. (1997), Capturing the heart of leadership: Spirituality and community in the new American workplace, Praeger Publishers, Westport, Connecticut.

Fredrickson, B.L. (2003), "Positive emotions and upward spirals in organizations", in: Cameron, K.S., Dutton, J.E., Quinn, R. (Eds.), Positive organizational scholarship, Berrett-Koehler, San Francisco, pp. 163-175.

Fredrickson, B.L., Losada, M.F. (2005), "Positive affect and complex dynamics of human flourishing", American Psychologist, Vol. 60 No. 7, pp. 678-686. DOI: 10.1037/0003-066X.60.7.678

Fry, L.W. (2003), "Toward a theory of spiritual leadership", The Leadership Quarterly, Vol. 14 No. 6, pp. 693-727. DOI: 10.1016/j.leaqua.2003.09.001

Furnham, A., Brewin, C.R., O'Kelly, H. (1994), "Cognitive style and attitudes to work", Human Relations, Vol. 47 No. 12, pp. 1509-1521. DOI: 10.1177/001872679404701204

Furnham, A., Sadka, V., Brewin, C.R. (1992), "The development of an occupational attributional style questionnaire", Journal of Organizational Behavior, Vol. 13 No. 1, pp. 27-39. DOI: 10.1002/job.4030130104

Furnham, A., Sadka, V., Brewin, C.R. (1992), "The development of an occupational attributional style questionnaire", Journal of Organizational Behavior, Vol. 13 No. 1, pp. 27-39. DOI: 10.1002/job.4030130104

Gardner, W.L., Avolio, B.J., Luthans, F., May, D.R., Walumbwa, F. (2005), “Can you see the real me? A self-based model of authentic leader and follower development", The Leadership Quarterly, Vol. 16 No. 3, pp. 343-372. DOI: 10.1016/j.leaqua.2005.03.003

George, B. (2003), Authentic Leadership: Rediscovering the secrets to creating lasting value, Jossey-Bass, San Francisco. 
DRIVING

PERFORMANCE THROUGH POSITIVE

Sunil Kumar Ramdas Harold Andrew Patrick
George, B. (2016), “The Massive Difference between Negative and Positive Leadership", available at: http://fortune.com/2016/03/21/negative-positive-leadership-politics-fordalan-mulally

Glynn, M., Dowd, T.J. (2008), "Charisma (un)bound: Emotive leadership in Martha Stewart living magazine”, The Journal of Applied Behavioral Science, Vol. 44 No. 1, pp. 71-93. DOI: 10.1177/0021886308314461

Goleman, D., Boyatzis, R.E., McKee, A. (2002), "Primal leadership: Realizing the power of emotional intelligence", Harvard Business School Press, Boston.

Gordon. J. (2017), “The Power of Positive Leadership”, available at: http://jongordon.com/ books/positiveleadership/

Grawitch, M.J., Gottschalk, M., Munz, D.C. (2006), “The path to a healthy workplace: A critical review linking healthy workplace practices, employee well-being, and organizational improvements", Consulting Psychology Journal: Practice and Research, Vol. 58 No. 3, pp. 129-147. DOI: 10.1037/1065-9293.58.3.129

Greenleaf, R.K. (1991), The servant as leader, Robert K. Greenleaf Center, Indianapolis. Greenleaf, R.K. (1970), The servant as leader, Robert K. Greenleaf Publishing Center.

Hakimi, N., Van Knippenberg, D., Griessner, S. (2010), "Leader empowering behaviour: The leader's perspective”, British Journal of Management, Vol. 21 No. 3, pp. 701-716. DOI: $10.1111 / \mathrm{j} .1467-8551.2010 .00703 . x$

Haney, B. (2012), "Charismatic leaders: They are beacons of positivity", available at: http://www.executiveforums.com/resources/le1112.pdf

Helland, M.R., Winston, B.E. (2005), “Towards a deeper understanding of hope and leadership",

Henry, P.C. (2005), "Life Stresses, Explanatory Style, Hopelessness, and Occupational Class", International Journal of Stress Management, Vol. 12 No. 3, pp. 241-256. DOI: 10.1037/1072-5245.12.3.241

Henryhand, C.J. (2009), "The effect of employee recognition and employee engagement on job satisfaction and intent to leave in the public sector", Doctoral dissertation, available at: http://gateway.proquest.com/openurl?url_ver=Z39.882004\&res_dat=xri:pqdiss\&rft_ val_fmt=info:ofi/fmt:kev:mtx:dissertation\&rft_dat=xri:pqdiss:3369470

Holland, B.M. (2000), "Bringing out the best in people: an interview with Warren Bennis", available at: https://thesystemsthinker.com/bringing-out-the-best-in-people-aninterview-with-warren-bennis

House, R.J. (1976), “Theory of Charismatic Leadership”, Working Paper Series 76-06.

Journal of Leadership and Organizational Studies, Vol. 12 No. 2, pp. 42-54. DOI: $10.1177 / 107179190501200204$

Kelloway, E.K., Weigand, H., McKee, M.C., Das, H. (2013), "Positive leadership and employee well-being”, Journal of Leadership \& Organizational Studies, Vol. 20 No. 1, pp. 107-117. DOI: 10.1177/1548051812465892

Konczak, L.J., Stelly, D.J., Trusty, M.L. (2000), "Defining and measuring empowerment leader behaviours: Development of an upward feedback instrument", Educational and Psychological Measurement, Vol. 60 No. 2, pp. 301-313. DOI: 10.1177/00131640021970420

Kouzer, M.J., Posner, Z.B. (1999), Encouraging the Heart: A leader's guide to rewarding and recognizing others, Jossey-Bass. 
Krueger, J., Killham, E. (2005), “At work, feeling good matters: Happy employees are better equipped to handle workplace relationships, stress and change according to the latest GMJ survey", available at: http://gmj.gallup.com/content/20311/ Work-FeelingGood-matters.aspx\#1

Liden, R.C., Wayne, S.J., Liao, Ch., Meuser, J.D. (2014), "Servant leadership and serving culture: Influence on individual and unit performance", Academy of Management Journal, Vol. 57 No. 5, pp. 1434-1452. DOI: 10.5465/amj.2013.0034

Linley, P.A., Govindji, R., West, M.A. (2007), "Positive psychology approaches to public services leadership: An introduction to strengths-based leadership", The International Journal of Leadership in Public Services, Vol. 3 No. 4, pp. 44-55.

Linley, P.A., Harrington, S. (2006), "Strengths coaching: A potential-guided approach to coaching psychology", International Coaching Psychology Review, Vol. 1 No. 1, pp. 37-46.

Luthans, F., Avolio, B.J. (2003), “Authentic leadership development”, in: Cameron, K.S., Dutton, J.E., Quinn, R.E. (Eds.), Positive Organizational Scholarship. Foundations of a new discipline, Berrett-Koehler Publishers, San Francisco, pp. 241-259.

Luthans, K. (2000), "Recognition: A powerful, but often overlooked, leadership tool to improve employee performance", The Journal of Leadership Studies, Vol. 7 No. 1, pp. 31-39. DOI: 10.1177/107179190000700104

Lyubomirsky, S., Sheldon, K.M., Schkade, D. (2005), "Pursuing happiness: The architecture of sustainable change", Review of General Psychology, Vol. 9 No. 2, pp. 111-131. DOI: 10.1037/1089-2680.9.2.111

Maidique, M.A. (2013), "Positive Leadership. Center for Leadership Current Research", available at: http://digitalcommons.fiu.edu/lead_research/4

Manz, C.C., Sims, H.P. (1990), Super Leadership, Berkeley Books, New York.

Meng, H., Cheng, Z., Guo, T. (2016), "Positive team atmosphere mediates the impact ofauthentic leadership on subordinate creativity", Social Behavior and Personality, Vol. 44 No. 3, pp. 355-368.

Meyer, J., Allen, N. (1991), “A Three-Component Model Conceptualization of Organizational Commitment”, Human Resource Management Review, Vol. 1 No. 1, pp. 61-89. DOI: 10.1016/1053-4822(91)90011-Z

Nel, T., Stander, M.W., Latif, J. (2015), “Investigating positive leadership, psychological empowerment, work engagement and satisfaction with life in a chemical industry", Journal of Industrial Psychology, Vol. 41 No. 1. DOI: 10.4102/sajip.v41i1.1243

Nolan-Hoeksema, S., Girgus, J.S., Seligman, M.E.P. (1986), "Learned helplessness in children: A longitudinal study of depression, achievement and explanatory style", Journal of Personality and Social Psychology, Vol. 51 No. 2, pp. 435-442. DOI: 10.1037/0022-3514.51.2.435

Patrick, H.A., Sunil, K.R. (2019), "Does trust in the workplace influence work engagement? An investigation among information technology employees", International Journal of Advance and Innovative Research, Vol. 6 No. 1, pp. 126-133.

Peterson, C., Barrett, L.C. (1987), "Explanatory style and academic performance among university freshman", Journal of Personality and Social Psychology, Vol. 53 No. 3, pp. 603-607. DOI: 10.1037/0022-3514.53.3.603 
DRIVING

PERFORMANCE THROUGH POSITIVE

Sunil Kumar Ramdas Harold Andrew Patrick
Peterson, C., Seligman, M.E.P. (1984), "Causal explanations as a risk factor for depression: Theory and evidence”, Psychology Review, Vol. 91, pp. 347-374.

Proctor, C., Maltby, J., Linley, P.A. (2011), "Strengths use as a predictor of well-being and health-related quality of life", Journal of Happiness Studies, Vol. 12 No. 1, pp. 153-169. DOI: 10.1007/s10902-009-9181-2

Quinn, R.E. (2005), "Moments of greatness: Entering the fundamental state of leadership", Harvard Business Review, July-August, pp. 75-83.

Quinn, R.E., Spreitzer, G.M. (1997), "The road to empowerment: Seven questions every leader should consider", Organizational Dynamics, Vol. 26 No. 2, pp. 37-49. DOI: 10.1016/S0090-2616

Recker, J., Mertens, W. (2017), Positive Deviance and Leadership: An Exploratory Field Study. DOI: 10.24251/HICSS.2017.025

Reivich, K., Shatte, A. (2002), The Resilience Factor, Broadway Books, New York.

Russell, R.F., Stone, A.G. (2002), "A review of servant leadership attributes: Developing a practical model”, Leadership and Organization Development Journal, Vol. 23 No. 3, pp. 145-157. DOI: 10.1108/01437730210424

Ryan, R.M., Deci, E.L. (2000), "Self-determination theory and the facilitation of intrinsic motivation, social development, and well-being", The American Psychologist, Vol. 55, pp. 68-78. DOI: 10.1037/0003-066X.55.1.68

Saleh, A. (2014), Leadership Development for Young People, The University Of Edinburgh.

Seligman, M.E., Schulman, P. (1986), "Explanatory style as a predictor of productivity and quitting among life insurance sales agents", Journal of Personality and Social Psychology, Vol. 50 No. 4, pp. 832-838. DOI: 10.1037/0022-3514.50.4.832

Seligman, M.E.P. (1998), "Positive social science", APA Monitor, Vol. 29 No. 2.

Spreitzer, G., Cameron, K. (2012), "Applying a POS to bring out the best in organizations", Organizational Dynamics, Vol. 41 No. 2, pp. 85-88. DOI: 10.1016/j. orgdyn.2012.01.001

Spreitzer, G.M. (1995), "Psychological empowerment in the workplace: Dimensions, measurement, and validation", Academy of Management Journal, Vol. 38 No. 5, pp. 1442-1465. DOI: $10.2307 / 256865$

Spreitzer, G.M., Sonenshein, S. (2004), "Toward the construct definition of positive deviance”, American Behavioral Scientist, Vol. 47 No. 6, pp. 828-847.

Tombaugh, R.J. (2005), "Positive leadership yields performance and profitability: Effective organizations develop their strengths", Development and Learning in Organizations: An International Journal, Vol. 19 No. 3, pp. 15-17. DOI: 10.1108/14777280510590031

van Dierendonck, D. (2011), "Servant leadership: A review and synthesis", Journal of Management, Vol. 37 No. 4, pp. 1228-1261. DOI: 10.1177/0149206310380462

Vianello, M., Galliani, E.M., Haidt, J. (2010), “Elevation at work: The effects of leaders' moral excellence”, The Journal of Positive Psychology, Vol. 5 No. 5, pp. 390-411. DOI: 10.1080/17439760.2010.516764

Walumbwa, F.O., Avolio, B.A., Gardner, W.L., Wernsing, T.S., Peterson, S.J. (2008), "Authentic Leadership: Development and Validation of a Theory-Based Measure", Journal of Management, Vol. 34 No. 1, pp. 89-126. DOI: 10.1177/0149206307308913 Wayne K.H., Smith, A.P. (2007), "Influence: a key to successful leadership", International Journal of Educational Management, Vol. 21 No. 2, pp. 158-167. 
Wood, A.M., Linley, P.A., Maltby, J., Kashdan, T.B., Hurling, R. (2011), “Using personal and psychological strengths lead to increases in well-being over time: A longitudinal study and the development of the strengths use questionnaire", Personality and Individual Differences, Vol. 50 No. 1, pp. 15-19. DOI: 10.1016/j.paid.2010.08.004

Youssef-Morgan, C.M., Luthans, F. (2013), "Positive leadership: Meaning and application across cultures", Organizational Dynamics, Vol. 42 No. 3, pp. 198-208. DOI: 10.1016/j.orgdyn.2013.06.005

Yulk, G. (2011), Leadership in Organisation, Pearson Education, Dorling Kindersely, India.

Zbierowski, P. (2016), "Positive leadership - attempt to clarification and assessment of novelty", Journal of positive Management, Vol. 7 No. 4, pp. 61-70. DOI: 10.12775/ JPM.2016.023

Zbierowski, P., Góra, K. (2014), "Positive leadership: Its nature, antecedents and consequences", Journal of Positive Management, Vol. 5 No. 1, pp. 85-99. DOI: 10.12775/ JPM.2014.008 